\title{
Cuando la Historia se hace historia: (re)creación de Pancho Villa por Nellie Campobello en Los apuntes sobre la vida militar de Francisco Villa (1940)
}

\author{
Jeromine FRANÇOIS \\ Université de Liège
}

\section{RESUMEN}

Este artículo lleva a cabo un análisis del texto de la escritora Mexicana Nellie Campobello, Los apuntes sobre la vida militar de Francisco Villa, en el cual el personaje histórico y su protagonismo en la Revolución mexicana pasan a convertirse en una historia novela en la que realidad y ficción rompen sus fronteras.

Palabras clave: Nellie Campobello, Pancho Villa, Revolución mexicana, biografía, ficción.

When the History does history to itself: (re) Pancho Villa's creation for Nellie Campobello in Los apuntes sobre la vida militar de Francisco Villa

\begin{abstract}
This article carries out an analysis of the text of the writer Mexicana Nellie Campobello, Los apuntes sobre la vida militar de Francisco Villa, in which the historical personage and his protagonism in the Mexican Revolution happen to turn into a history writes novels in that reality and fiction break his borders.
\end{abstract}

Key words: Nellie Campobello, Pancho Villa, Mexican Revolution, Biography, Fiction.

\section{Introducción}

No son pocas las afinidades que relacionan a Nellie Campobello con el revolucionario Pancho Villa. Contemporánea suya, la madre de Campobello era villista y transmitió a su hija su admiración por el guerrero revolucionario. Además, aunque puedan resultar anecdóticos, los parecidos vitales entre la escritora y Villa no dejan de ser curiosos. Los dos son originarios de Durango y, además, ambos experimentaron un cambio onomástico: Doroteo Arango eligió el seudónimo de Francisco Villa (Berumen, 2006, 34) y Francisca Moya Luna adquirió el seudónimo de Nellie Campobello hacia 1923 (Bautista Aguilar, 2007, 12). Nótese también que 
Nellie se llamaba a sí misma la Centaura del Norte en referencia al apodo de Villa, el Centauro del Norte. Por fin, ambos murieron "metafóricamente asesinad(os) o borrad(os) de la Historia o de su propia historia" (Glantz, 2003, 20). Por lo demás, Campobello crea al general como personaje en Cartucho y en Las manos de mamá antes de dedicarle un texto íntegro titulado los Apuntes sobre la vida militar de Pancho Villa y publicado en 1940.

Es sintomático que cuando la crítica se acerca a esta obra, suceso que no ocurre con mucha frecuencia, ya en su manera de presentarla se percibe cierta vacilación en cuanto a su definición genérica. Para Ruano Gutiérrez $(2010,7)$ se trata de "un relato de hechos armados" mientras que para Christopher Domínguez (citado por Ruano Gutiérrez, 2010,7) pertenecería a la épica menor. Según Parra $(2005,69)$, el texto se asemeja en el fondo a un "historical book" pero, para Gutiérrez de Velasco (2006, 99), mejor se calificaría como "un breve tratado de estrategia sobre las andanzas militares del héroe revolucionario". En fechas más recientes, Vanden Berghe $(2010,151)$ define estos Apuntes como "un libro de memorias de Pancho Villa". Aunque estas categorizaciones genéricas parecen atestiguar la raigambre fundamentalmente histórica de los Apuntes, la intención de la autora, tal y como la expone en la "Nota preliminar" que abre el relato estudiado, y tal y como la reafirmará posteriormente en el "Prólogo" a Mis libros, no deja de llamar la atención: esta obra quiere proporcionar una versión verdadera de los hechos, exenta de las construcciones de la historia oficial. Asimismo, Parra $(2005,54)$ ve en los Apuntes de Campobello "the culmination of a personal campaign to rehabilitate Villa in the public's memory". En efecto, la meta que se propone la escritora mexicana consiste en demostrar el carácter positivo de la actuación de Villa durante la Revolución: "Hago constar que este Francisco Villa nada tiene que ver con el protagonista de tantas historias falsas y leyendas ridículas. La persona a la que se refieren estos apuntes tuvo una vida ejemplar como soldado. Dio batallas gloriosas las más y las mejores habidas en México" ("Nota preliminar", 204). ${ }^{1}$

En estas páginas, quisiéramos partir de la ambiguëdad genérica de los Apuntes para estudiar el tratamiento que este texto reserva a Pancho Villa, figura vilipendiada por la clase dirigente antes de que iniciara su rescate el presidente Lázaro Cárdenas. De hecho, la hibridez genérica parece ser una constante de la obra narrativa, a la vez ficticia y referencial, de Nellie Campobello. ${ }^{2}$ En el caso concreto de los Apuntes, nos apoyaremos en la teoría de Hayden White para argumentar sobre la recuperación de técnicas propias del relato histórico que son subvertidas

${ }^{1}$ A partir de aquí, para cada cita extraída de las obras de Nellie Campobello, se indicará(n) entre paréntesis la(s) página(s) correspondientes en nuestra edición de 2007.

2 Tanto Cartucho como Las manos de mamá suscitan la polémica en cuanto a su categorización genérica. 
por recursos propiamente literarios. Así iremos destacando el constante oscilar entre el polo histórico y el polo literario para cada punto de análisis, de tal modo que cuestionaremos primero la estructura del texto, para más adelante tratar el modo de narración que lo caracteriza, así como el estilo que lo conforma, antes de reflexionar acerca del personaje de Villa que se da en los Apuntes como una construcción original. Después, veremos cómo esta combinación de procedimientos históricos y literarios permite llevar a cabo, más allá del sencillo rescate, una verdadera mitificación del personaje histórico de Pancho Villa. Al fin y al cabo, considerar el texto de Campobello desde una perspectiva genérica nos conducirá a interpretar esta creación "moderna" de un mito como un producto híbrido que nace cuando historia y literatura entran en consonancia.

Está constatado que el propósito histórico que reivindica la escritora deriva en los Apuntes hacia una argumentación fuertemente orientada que constituye un verdadero panegírico del guerrero. ${ }^{3}$ ¿Podemos tildar de "histórico" un texto así? Según Halkin (1991) y White $(1992,1999,2006)$ un texto histórico, al menos en su versión contemporánea y siguiendo las pautas establecidas por la crítica histórica, debe presentar un discurso científico que se basa en fuentes y se propone discernir entre lo verdadero y lo falso. El historiador intenta ser lo más objetivo posible, ser consciente de la precariedad de su texto, y tiene que aceptar la posibilidad de replanteamientos. Ahora bien, aunque la autora afirma su voluntad de restablecer la verdad histórica, la objetividad (que es justamente la condición del género histórico) es deslucida por esta petición de principio que Campobello repite en su "Prólogo": se trata de arrojar "a los malos (el discurso oficial) que despojaron y asesinaron a los buenos (Villa y los villistas)" (371).

De hecho, esta ambigüedad genérica puede relacionarse con las teorías de Hayden White. Éste considera que cualquier texto histórico es un artefacto literario, puesto que los acontecimientos históricos no hablan por sí solos y que, si se quiere dar a entender la historia, uno tendrá que narrativizarla. Así el historiador no se contenta con registrar cronológicamente los hechos sino que también selecciona los sucesos y los dota de una estructura. La historia se transforma por tanto en relato. A través de la narración, lo histórico se hace más comprensible y se vuelve significante.

White precisa que el historiador sólo impone una significación al material histórico bajo los condicionamientos de su propio horizonte histórico y de sus intereses y objetivos particulares. En efecto, la percepción del texto histórico así como su relación con la narración varían según las épocas. De hecho, White señala

3 Ahora bien, Halkin (1991) apunta que, aunque la biografía, cuyo objeto es la transmisión verídica de una personalidad, es "un genre historique comme les autre" (115), "un éloge n'est pas une histoire” (118), puesto que aquí no cabe la crítica histórica. 
ciertos períodos particulares como las revoluciones que "are destitute of any 'objective history" $(1992,12)$. Ahora bien, la publicación de los Apuntes se sitúa justamente en una époc a de reconstrucción nacional que sigue una revolución, la Revolución mexicana. Es más, escribir sobre unos episodios de la historia reciente sin duda incita a que Campobello atribuya a esta historia un valor peculiar. Concretamente, el tratamiento narrativo que experimenta la figura histórica de Pancho Villa al estar integrada en los Apuntes nos revela el proceso de rescate y aun de mitificación que pone en marcha Campobello hacia un personaje cuya rehabilitación todavía era espinosa.

\section{Estructura}

Según Pratt (2004), las dos obras narrativas principales de Campobello, Cartucho y Las manos de mamá, muestran que la autora logró una "forma alternativa de historicidad para contar los eventos de la revolución" (255). Con los Apuntes, cuya publicación es posterior, la mexicana parece curiosamente dar un paso atrás en esta renovación genérica. En efecto, la estructura de este texto es en todo conforme a un relato histórico clásico. Los Apuntes se dividen en diez capítulos de longitud variable, cada uno de ellos introducido por un encabezamiento que sigue el título de la sección y que consiste en una serie de proposiciones nominales separadas por rayas. El conjunto proporciona un resumen sucinto de lo que tratará el capítulo. ${ }^{4}$ Sin embargo, sucede que aparecen varios encabezamientos estructurando el mismo apartado en varios subcapítulos. Estos principios estructurales confieren al texto un aspecto neutro y científico por el rechazo de ornamento que evidencian. El lector tiene la impresión de leer un diario de campaña militar, como inducen a pensar los títulos de los capítulos. En efecto, éstos se construyen, con excepción del primer y del último capítulo, del mismo modo: "De la campaña de + año". Gutiérrez de Velasco explica la función de dicho proceso de la manera siguiente:

[...] con el objeto de involucrar a sus lectores en el desarrollo de esa vida militar, Nellie Campobello crea una intriga que trata de prescindir de conocimientos previos, como si se contara una historia por primera vez; y también la autora antecede cada capítulo con una serie de puntos que resumen el contenido de manera inquietante. (2006: 100)

\footnotetext{
${ }^{4}$ Véase el siguiente ejemplo de tal encabezamiento que se coloca después del segundo capítulo "De la campaña de 1912": "Villa maderista.-Huerta, jefe de Villa._Parral.Rábago.--Rubio Navarrete.-El fusilamiento.-Testimonios.- Su prisión y su fuga.” (208).
} 
Ya se vislumbra el papel desempeñado por la temporalidad en este texto, pues, como en todo texto histórico, se trata de la principal herramienta a la que recurre el autor para estructurar su materia. El orden cronológico que condiciona el relato está omnipresente y siempre riguroso, tanto en los títulos de los capítulos como dentro del mismo texto. Esto se debe a que "the regularity of the calendar signals the "realism" of the account" (White, 1992, 8). Es de notar que el orden nítidamente cronológico en la mayor parte del relato se rompe a veces por la inserción de ciertas prolepsis. Sin embargo, éstas sirven dentro de la argumentación, ora para enunciar de antemano las victorias de Villa (lo cual reafirma sus competencias), ora para evocar las difamaciones futuras que contrastan entonces con el valor militar que justamente se está demostrando. Ahora bien, el período escogido por Campobello no es casual, visto que entre 1912 y 1919 ocurrieron las hazañas villistas que tuvieron más impacto y que participaron en la posterior mitificación de Villa, como su evasión, la toma de Torreón, el nombramiento del centauro como general, la toma de Ciudad Juárez, el combate de Tierra Blanca o la campaña de Ojinaga. Como arguye White $(1992,9)$ "it is only from our knowledge of the subsequent history of Western Europe that we can presume to rank events in terms of their world-historical significance". A decir verdad, esta selección y organización cronológica de los episodios de la vida militar de Pancho Villa, además de corresponder a los requisitos del género histórico, también permiten llevar a cabo una evolución del personaje, según un esquema literario, desde la génesis de su cara guerrera hasta su nacimiento como leyenda.

Por otra parte, el cuadro narrativo de los Apuntes puede estudiarse desde un enfoque literario como perfecto exponente de la confluencia del relato de guerra clásico y del relato de guerra moderno, según la terminología establecida por Kaempfer (1998). Efectivamente, ciertas luchas se describen según el esquema del relato de guerra clásico, puesto que proporcionan al lector una clara distribución de los actantes, como si éste fuera un espectador exterior de un juego de ajedrez, repartidos en dos campos (los buenos y los malos), así como una posibilidad de entender el desarrollo de la batalla y de racionalizarla, como se muestra claramente en el siguiente fragmento:

Los villistas se reúnen y, de acuerdo con el General en Jefe, resuelven dar el asalto final esa noche. Se dispone que ataque el general Urbina, comandante del centro en esos momentos, con las brigadas Morelos, Villa, Ortega y Guadalupe Victoria, y la artillería respectiva. La derecha cuenta con Herrera, Trinidad Rodríguez, Ceniceros, y las brigadas Juárez, Cuauhtémoc, y la Juárez, de Durango. La izquierda con los generales Robles y con las brigadas Robles, Zaragoza y Hernández. Se corren las órdenes y empieza el avance, que se traduce en el triunfo absoluto de los villistas. El enemigo huye, con él escapan los civiles enemigos de la Revolución. (239) 
Ahora bien, otras batallas no son tan claras ni tan racionalizadas sino que se describen mediante una cronología condensada, un ritmo de la narración acelerado y el enfoque en un personaje en concreto, características que impiden la transparencia de una guerra que se cuenta desde afuera. El relato de guerra se hace así moderno cuando asistimos a la maniobra aislada de Martín López que, en medio del bando enemigo, espera con angustia la señal de Villa que no viene.

\section{Modo de narración}

Al combinar ambos tipos de relato de guerra, los Apuntes varían también el modo de narración, pasando con fluidez de la focalización cero a la focalización externa. Conviene entonces contrastar el modo propiamente histórico y el modo más literario de regular la información narrativa que combina nuestro texto. Los estudios históricos suelen caracterizarse por un narrador discreto, omnisciente cuando pretende abarcar un objeto de estudio de manera completa, o por un narrador que nos relata los hechos mediante una focalización externa que le permite seguir la acción con una cámara dirigida hacia un personaje en concreto pero sin entrar en sus pensamientos. El narrador de los Apuntes no duda en recurrir a palabras ajenas para dar más validez a su discurso. Así se refiere de manera recurrente a sus fuentes ${ }^{5}$ y se insertan documentos históricos oficiales ${ }^{6}$ : "cuentan los supervivientes que" (206), "el coronel Timoteo Cuéllar, veterano de aquella jornada, ha contado que" (240), "según dicen los libros históricos" (265) etc.

Por otra parte, esta discreción del narrador histórico se acompaña de un estilo impersonal que no aparece en Campobello. En efecto, el narrador de los Apuntes se individualiza mediante la fuerte presencia de una primera persona del singular que insufla juicios de valor en su texto: "he dicho que" (268), "yo considero" (288). Asimismo, el distanciamiento cronológico del narrador respecto a los hechos que cuenta y la transcripción de las declaraciones de los personajes, mediante algunos récits de paroles en discurso directo o indirecto, desempeñan un papel doble, otra vez a caballo entre los códigos de la historia y las pautas literarias. En efecto, aunque el distanciamiento cronológico sirve en textos históricos para asegurar la objetividad del narrador que estudia los hechos desde una perspectiva ensanchada, aquí esta distancia temporal permite al narrador valorar el pasado según el momento presente en que se escribe, desde ese "ahora (cuando) el tiempo nos ha enseñado la verdad" (270). Pensándolo bien, Nellie Campobello también impone sentido y

${ }^{5}$ En la "Nota preliminar", Campobello desgrana sus fuentes: sus conversaciones con la viuda Austreberta Rentería Villa, el archivo de Villa, sus conversaciones con algunos dorados y con Martín Luis Guzmán y su visita de los lugares de batalla.

${ }^{6}$ Se incluyen por ejemplo en los Apuntes un telegrama de Huerta o una declaración de Villa durante su juicio. 
fuerza a los personajes, y sobre todo al personaje de Villa cuya voz está muy presente en el texto, por medio de los récits de paroles: los monólogos y los diálogos caracterizan a los personajes y así cumplen la función de las descripciones que escasean en los Apuntes. Gracias a la abundancia de discursos directos que transmiten las conversaciones de Villa, éste se define por una palabra sincera, sin pretextos falsos, que contrasta con las maniobras oratorias poco claras de sus enemigos.

\section{Estilo}

El detallismo ${ }^{7}$ del estilo de Campobello parece abogar por una influencia del estilo histórico. Tanto el vocabulario técnico como las referencias con precisión matemática a los nombres de los diferentes actores históricos o de lugares, a cifras o a inventarios de fuerzas y de armas, participan en esta tecnicidad del estilo que a veces se vuelve casi áspero. ${ }^{8}$ El relato así hace alarde de una exactitud minuciosa que revela un estudio bien documentado. Por lo demás, el narrador parece conferir aún más verosimilitud a su relato al recurrir sistemáticamente a un estilo afirmativo y al campo semántico del saber. En realidad, formulaciones tipo "hago constar que" (203), "indudablemente" (205), "es mentira que" (206), "la verdad es que" (245), o "puedo asegurar que" (266), (288) son herramientas para convencer, y forman más parte de la argumentación orientada de la autora que de un verdadero discurso histórico. Dicho de otro modo, el historiador profesional nunca pretenderá entregar al lector una verdad absoluta y jamás sacará partido de afirmaciones tan tajantes como "no hay que agregar una palabra más" (269). ${ }^{9}$ Nótese que el estilo aforístico, formulaico o sentencioso que caracteriza muchas veces este texto forma parte de la misma dinámica argumentativa. Por ejemplo, frases semejantes a "la verdad de sus batallas es la verdad de su vida" (203), "con la seguridad que sólo tienen las gentes que han sufrido" (205) o "en esta forma peleaban y en esta forma morían" (295) visten la forma de aforismos conclusivos.

Los numerosos juegos estilísticos de los Apuntes sólo pueden asombrar al lector que quiere entender este texto en clave exclusivamente histórica. Concretamente, además de los adverbios u otros giros que introducen pathos, suspense y aun

7 “[...] se escudriñan las escenas” según Juan Bautista Aguilar (2007, 23).

${ }^{8}$ Véase este fragmento: “Al general José Rodríguez, al mando de la Brigada Villa, con 500 hombres; 550 de la Brigada Morelos, al mando de Faustino Borunda; 400, de la Brigada Contreras, al mando de Luis Días Crider; dos baterías de 75 y 80 milímetros al mando de Martiniano Servín; un regimiento de ametralladoras, al mando de Margarito Gómez" (230).

${ }^{9}$ Suscribimos el comentario de White $(2006,16)$ : uno de los rasgos distintivos de un buen historiador profesional es que éste recuerda siempre a sus lectores la índole provisional de las conclusiones que saca de su estudio de sucesos y actores del pasado. Asimismo, el historiador no duda en afirmar el carácter incompleto de la mayoría de sus fuentes. 
sorpresa en la narración, ${ }^{10}$ no son pocas las repeticiones de fórmulas cargantes que ritman la obra. Bastan como ejemplos significativos la recurrencia de la expresión "a sangre y a fuego" $(274,291,305,307$ etc.) o la exclamación "iViva Villa!" que cierra cada relato de una hazaña militar particularmente relevante y que acerca el texto a una mera propaganda: "Al grito de ¡Viva Villa! cayó aquella plaza, y al grito de ¡Viva Villa! caerían todas las demás, y durante años este grito sería el terror de los traidores. Es todavía una contraseña de valor el grito de ¡Viva Villa!” (232). Junto con Parra (2005, 54-55), podemos afirmar que "these stylistic devices reveal an acute sense of rythm and an appreciation for the materiality of language". De hecho, la índole literaria de este ritmo estriba en una adecuación de la forma con el contenido: se recrea el movimiento apurado de las batallas, la prisa y la rabia que las conforman, mediante un estilo entrecortado de frases breves, averbales y a veces sin conectores, que se yuxtaponen de manera paratáctica:

Una columna villista, sin obedecer más órdenes que su deseo y el ciego impulso de su cólera, esperó al enemigo. Los dejaron acercar, y a distancia de unos cuantos metros les hicieron fuego. Así, así, casi a quemarropa y a los gritos de "Viva Villa“..., “¡Abajo, gringos hijos de tal!”... “¡Éntrenle, desgraciados, que aquí están sus padres!”... (303)

Este estilo permite que, en más de una ocasión, el narrador ensalce la sangre fría de Villa que siempre encuentra la mejor estrategia para aprovecharse del peor marasmo. Otras veces, se agrega al ritmo fragmentado de la narración una visión fragmentada de los cuerpos y de las armas para reflejar mejor la debacle y la violencia del conflicto: "bocas, ruedas de cañones, manos, pies y ojos de hombres, clarines, fusiles y tambores, todo es aplastado de un solo golpe" (306). Por otra parte, el estilo también deja de ser neutro cuando multiplica las preguntas retóricas o cuando se hace enfático, al pulular los superlativos y las hipérboles. Las preguntas retóricas confieren un carácter exclusivo a los éxitos del general: "¿Quién pudo antes que Villa hacer en México una carrera más gloriosa? ¿Quién pudo antes que él formar un ejército tan completo, competente y numeroso? ¿Y esa campaña suya, continuada e incansable?" (220). El énfasis no admite que se contradigan sus afirmaciones: Villa es "el único guerrero de su tiempo, uno de los más grandes de la historia; el mejor de América y después de Gengis Kan, el más grande guerrero que ha existido" (203), "este asalto (villista) es la acción de guerra más grande que se registra en la historia revolucionaria" (238). ${ }^{11}$

10 "furiosamente" (240), "rudamente" (241), "nadie se imagina lo que va a pasar" (241), "lo raro es que" (268), "con increíble facilidad" (268), "no había tiempo que perder" (303).

${ }^{11}$ Las cursivas que evidencian lo superlativo de los fragmentos son nuestras. 
Según White $(2006,30)$, el historiador organiza y da sentido a su materia mediante cuatro tropos principales, de índole claramente literaria: la metáfora, la metonimia, la sinécdoque y la ironía. Sobra decir que los Apuntes sí están pletóricos de figuras retóricas, lo que permite, como percibe Gutiérrez de Velasco $(2006,100)$, que el texto no fuera "un descarnado relato de batallas". Así se legitima la sublevación militar de Villa mediante una delicada comparación extraída del mundo natural: "su rebeldía era clara y limpia; las aves también la sienten cuando la mano del hombre las aprisiona" (204). Pero aparte de este uso de figuras retóricas como clave de lectura de la historia, en los Apuntes florecen metasemas que funcionan como puros juegos poéticos. Así, se presenta a Villa en su papel de líder: "apareció Francisco Villa montado en brioso caballo, dócil al jinete que lo maneja. Su cara era un sol rojo y parecía dar vida a sus hombres hasta invadirlos con su fuego y hacerlos pelear como leones prisioneros" (302). En este fragmento, se mezclan el campo léxico del encarcelamiento, recurrente en la obra, y una serie de figuras retóricas basadas en la isotopía de la fuerza (brioso, sol, fuego, leones) y en el color ígneo (sol rojo, fuego, leones) que van de la identificación ("su cara era un sol rojo") a la comparación ("pelear como leones prisioneros"), pasando por la metáfora ("fuego" por "vitalidad", "anhelo guerrero"). En cuanto a la ironía, ésta sólo se ataca a los detractores de Villa, aunque éstos fueran más bien víctimas de insultos patentes por parte del narrador.

Por su función laudatoria, el texto de Campobello hace pensar en la épica, forma literaria que comparte con la historia un mismo ámbito puesto que la epopeya da cuenta de las hazañas de héroes memorables que son dignas de recordarse. Sin embargo, cabe recordar que el historiador, cuyo texto es discurso, cuenta la historia explicándola, mientras que el poeta épico, cuyo texto es canto, cuenta la historia celebrándola. En este marco, Nellie Campobello opera una combinación de su cosecha: la explicación propiamente histórica está presente y se vuelve argumentación para defender y celebrar a Villa: el discurso sirve el canto. Tal y como Georg Lukacs lo explica en su Teoría de la novela (1963), la epopeya es un producto cultural "de l'ère des civilisations closes". Éstas se definen como épocas en las que cada uno sabe con claridad en qué consiste su deber y lo que son el Bien y el Mal. De hecho el maniqueísmo, es decir la dicotomía entre el Bien (Villa, los villistas y el pueblo mexicano) y el Mal (Carranza, los EE.UU. y los detractores de Villa), es tan tajante en los Apuntes que bien podríamos aprehenderlo a la luz de esta teoría. Además, dos tipos de períodos pueden funcionar como civilizaciones cerradas. Primero, el tiempo de guerra, cuando se realiza una unión contra el enemigo. Justamente lo que nos cuentan los Apuntes es un estado de guerra en el que el pueblo mexicano no duda en tomar el partido de Villa contra los dictadores o contra los americanos. El segundo tipo de período evidenciado por su predisposición a lo épico es el que sigue un desgarro nacional. No hace falta recordar que Campobello justamente se encuentra en tal etapa, visto que escribe su relato después de un conflicto interno mexicano. 
Sin embargo, la afinidad de los Apuntes con el género épico no se reduce a tales factores circunstanciales. Desde luego, es evidente que la dimensión popular de la epopeya, en la que suele expresarse la fe del pueblo en su héroe que combate para él, es alegremente recuperada por Campobello. Consabido es que la noción de "acto heroico" es central en el cantar de gesta y se define como una acción digna de recordarse. Ahora bien, una acción sólo podrá grabarse en la memoria épica si conlleva una dimensión colectiva, es decir si concierne "une communauté humaine dont les héros sont solidaires, soit qu'ils s'en fassent les champions, soit qu'en leur destin personnel se résume celui de la collectivité" (Martin y Gaillard, 1990, 28). Esta identificación del individuo con la comunidad es sobresaliente en el caso del Villa de los Apuntes: "sus ideales eran los del pueblo" (223), "el pueblo (...) siempre estuvo al lado de Villa" (277). El general poco a poco llega a simbolizar el poder del pueblo rural, ${ }^{12}$ y construir cierta imagen de Villa y de sus seguidores equivaldría por lo tanto a construir cierta identidad para el Norte de México: "ellos eran el pueblo, eran la masa campesina que venía a la ciudad a imponer su ley" (265).

Luego, la exaltación del valor en el combate y la cuestión de la honra, fundamental para cualquier héroe épico — véase como ejemplo hispánico el Cid cuyo honor se empeña en restaurar-, permiten oponer rotundamente los enemigos, miedosos y traicionadores, a los villistas, valientes y gloriosos aun en la muerte (272). A este respecto, debemos decir que el estilo superlativo que caracteriza el texto aquí estudiado en buena parte corresponde al estilo de los cantares de gesta, marcados por la exageración épica. El enemigo siempre es mucho más potente que Villa (303), pero también pierde mucho más hombres que el general (298). Asimismo, todas las ciudades tomadas por Villa son inexpugnables. Por fin, la jerarquía militar de Villa aparece marcada con el sello de la feudalidad: los aliados de Villa actúan como vasallos que deben fidelidad, afección y servicio a su señor. Por lo tanto, no nos extraña la insistencia con la que el narrador de los Apuntes incrimina recurrentemente a los traidores del general, titulando un subcapítulo "Las traiciones al general Villa". De hecho, gracias al empleo de este tópico épico, Campobello consigue poner en tela de juicio el principio de funcionamiento de la Revolución que quizá falseó sus logros: el sistema de alianzas y traiciones incesantes.

12 "The popular revolutionnary leader was [...] regarded by all segments of Mexican society as a vivid and forceful expression of the people's power, pride, and resilience" (Parra, 2005, 4). De hecho, esta dimensión popular del relato también podría cuestionarse a la luz de los comentarios de Ruano Gutiérrez $(2010,1)$ que apunta los vestigios propios del modelo del romanticisimo en la narrativa de la Revolución mexicana. 


\section{Construcción del personaje de Villa}

Visto que Villa constituye el elemento actancial central del texto de la autora mexicana, no ha de extrañar el hecho de que la construcción de este personaje de carne convertido en personaje de papel movilice, como acabamos de verlo, una consecuente red de procedimientos temáticos y estilísticos. Pero hay más: el protagonista de los Apuntes se construye también mediante leitmotivs que se combinan. En cualquier caso, Nellie Campobello se aprovecha de las características notorias del personaje (es decir el Villa histórico) y las resemantiza con el fin de ora pulir su alabanza, ora batir en brecha los estereotipos vehiculados por los enemigos de Villa.

El leitmotiv se actualiza bajo la forma de perífrasis, de adjetivos, de motivos más diluidos en el texto, o incluso mediante comparaciones. Éstas tienden a identificar a Villa con los grandes guerreros y estrategas de la historia: "ya en estos momentos la figura de Villa va saliendo de su tumba y poco a poco empieza a ocupar el sitio que le corresponde entre los grandes caudillos militares" (227). Aunque tanto Gengis Kan, ${ }^{13}$ von Schlieffen o Aníbal actúan como prestigiosos antecedentes de Villa, éste se compara preferentemente con la figura napoleónica, a la que se alude con más frecuencia y a la que se refiere el título del último capítulo "Recorrido napoleónico". Así ciertas citas del francés sirven para apuntar el arte militar del mexicano: "Decía Napoleón que «el arte de la guerra es sencillo y es todo ejecución». Villa siempre supo ejecutar" (219-220). De hecho Campobello no inventa este tipo de comparación sino que ensancha el abánico de las correspondencias entre Villa y otros estrategas establecidas por la prensa que ya llamaba al general "el Napoleón mexicano" y lo comparaba con Atila (Berumen, 2006, 41).

En general, son pocas las descripciones dedicadas al aspecto exterior del general, lo cual podría explicarse por la visión de éste que quiere propagar la autora: Villa, al contrario de muchos, es ante todo un hombre de acción y no de apariencias. En cambio, cuando sí se describe al Centauro del Norte, su retrato siempre se arraiga en una escena de combate, como si se sacara una foto en vivo y en directo, pero esta fotografía sería siempre parcial, visto que la descripción se centra casi metonímicamente en partes de su cuerpo: "La sonrisa franca del Centauro del Norte se hizo más amplia: fiereza en sus ojos, agilidad en sus manos, exactitud en sus tiros" (274), "los ojos del general no parpadeaban" (296), "sus ojos dorados se entrecierran" (312), "fila sus ojos de cobre en las caras de los muchachos" (312). Nótese que los ojos ya eran el punto de atracción de las descripciones del general que aparecían en el relato "Villa" que fue suprimido en la segunda edición de

13 "Fue el Gengis Kan de las llanuras del Norte" (271), "Villa y su gente sólo sabían pelear así, de cara al sol, y con la carabina en alto y a toda rienda, como lo hacían los gloriosos guerreros de Gengis Kan” (302). 
Cartucho. ${ }^{14}$ De hecho, los ojos funcionan realmente en los Apuntes como espejos del alma. Reflejan las aspiraciones sinceras tanto de Villa como de los mexicanos: "La gente pobre esperaba siempre el milagro de comer. Por eso los plomazos villistas reflejaban alegría en los ojos de los pobres" (305). El aspecto misterioso y ufano que se destaca de las descripciones de Villa sólo acrecienta, por comparación, lo ridículo del retrato de Carranza, gran enemigo de Villa. ${ }^{15}$

Otros motivos que se vinculan estrechamente con esta figura son la humildad, la valentía y la audacia: "un guerrillero ligero, muy valiente" (216), "el general Villa, con la audacia que lo caracterizaba" (226). Más específicamente, la autora otorga una preponderancia a dos motivos que eleva al rango de tópicos de los Apuntes, puesto que funcionan como lugares comunes de su retórica y que se actualizan bajo la forma de "fórmulas o clichés fijos y admitidos en esquemas formales o conceptuales" (DRAE, s.v. tópico). Estos motivos son, por un lado, el de la calumnia injusta, y, por otro lado, el de la derrota victoriosa. De entrada, la narradora anuncia que "la calumnia contra Francisco Villa ha cundido" (204) y se vuelve a insistir en la difamación del héroe en todo el texto, oponiéndose a los discursos de los "inmorales" (276), de los "ejércitos de aquella infeliz dictadura" (298), o de los "apologistas de los federales" (254). Aunque éstos declararon a Villa y a su ejército "horda de bandidos" (274), la superioridad del general permaneció intacta. Campobello explica racionalmente la propagación de las calumnias cuyo discurso retoma irónicamente:

Los escritores a su servicio (de Carranza) denostaban, difamaban y calumniaban a Villa y a sus hombres. Con ese espíritu de prejuicio existente en nuestra raza simple complejo de inferioridad - muchos generales revolucionarios empezaron a prestar oído a lo que se decía de Villa. Pero éste, el bandido, el hombre salvaje y el hombre inculto, jamás se ocupó de chismes. (264)

Por otra parte, Campobello reafirma la superioridad de Villa frente a sus detractores puesto que "ni siquiera vencido había perdido la guerra" (Gutiérrez de Velasco, 2006, 103). Dicho en otros términos, aun en la derrota se encuentra parte de victoria: "(Villa) no pudo tomar Chihuahua, cosa que le favoreció grandemente

14 “Cuando Villa estaba enfrente sólo se le podían ver los ojos, sus ojos tenían imán, se quedaba todo el mundo con los ojos de él clavados en el estómago", "levantó los ojos hasta mamá; todo él era dos ojos amarillentos medio castaños, le cambiaban de color en todas las horas del día", "«[...] hoy soy el padre de todas las viudas de mis hombres», dijo con los ojos hechos vidrio quebrado" ("Villa", primera edición de Cartucho).

15 “Carranza, sin ser propiamente gordo, era un poco panzón, tenía venas en las narices, signo inequívoco de los que comen mucho, y aunque no nos consta que tomara vino, sí tenía muchos poros en la sudorosa e inflexible nariz, bien ancha y llena de grasa" (264). 
en su campaña" (225); "derrota en el sentido exacto no existió" (267); "no hubo desastre ni derrota" (267). Este oxímoron de la derrota victoriosa se hace cada vez más presente a medida que avanza el relato y que la suerte del general ya no es tan clemente: es herido, traicionado, le faltan municiones... Por eso el tópico se hace sobre todo imperante en el capítulo dedicado a la campaña de 1915, año de duros reveses. Así se concluye en efecto dicho capítulo repitiendo el leitmotiv mediante la repetición de una pregunta retórica cuya recurrencia es apuntada por el propio narrador:

Demostraba así el ejército villista que, si brillantemente había actuado, brillantemente aceptaba perder, aunque, propiamente dicho, cuando la ofensiva falla a cientos de miles de kilómetros de su base, ¿cuál es la victoria del enemigo? El ejército de Villa se retira sin ser perseguido, insisto en mi pregunta: ¿Cuál fue la victoria del enemigo? (272)

Una de las razones que explican por qué no se acepta el fracaso de Villa se encuentra en la cara de justiciero que a él se asocia: "Villa era un defensor de los pobres y el vengador de Madero" (232), "los villistas traían gran suma de potencia moral: eran los vengadores de una afrenta, y ocurrían a imponer los derechos del pueblo" (233). En efecto, si se admite la derrota de este nuevo Libertador debe admitirse al mismo tiempo el fallo de los ideales revolucionarios que él encarna y que lo transforman en un Robin Hood mexicano:

[...] este nuevo líder montado y con espuelas representaba la rebelión contra la desigualdad de la riqueza. Cada peón deseoso de un pedazo de tierra en Chihuahua se emocionaba con una indirecta satisfacción cuando robaba ganado a los Terrazas, o cuando confiscaba fábricas o propiedades después de las batallas e imponía a los ricos contribuciones forzosas (Berumen, 2006, 37).

Dicho de otro modo, Villa roba a los ricos para ayudar a los pobres y es un perfecto exponente del bandido social ${ }^{16}$ : "todo lo que se llevó lo repartió a todas las familias" (286).

A fin de cuentas, aunque Campobello sólo se centra en la vertiente pública de la vida de Villa y no se acerca a su esfera privada, su tratamiento de esta figura

${ }^{16}$ Según este concepto, elaborado por Eric Hobsbawm (véase su estudio de 1959 Primitive Rebels: Studies in Archaic Forms of Social Movement in the 19th and 20th Centuries), el banditismo es social 'lorsqu'il s'attaque sélectivement aux riches et aux représentants de l'autorité politique, redresse les torts dont les pauvres sont victimes et donne une voix au mécontentement populaire. En échange, le bandit reçoit l'appui des masses populaires" (Lannoy, 1991, 287, n. 2). 
histórica consigue agregar "al apego de las fuentes fidedignas la dimensión humana del héroe" (Gutiérrez de Velasco, 2006, 99). En efecto la riqueza que se confiere a Villa estriba en la relación dialéctica entre sus contradicciones: los Apuntes logran sobrepasar la tensión que existe entre un campesino inculto y sentimenta ${ }^{17}$ y un jefe militar estratega y valiente. Así Villa combina todos estos componentes y su virilidad no le impide plasmar su sensibilidad ante las desgracias de su pueblo. Dentro del paradigma de la heroicidad, el texto quiebra el estereotipo según el cual "los hombres no lloran" (Glantz, 2001, 15): "el hombre de la sierra lloraba de rabia" (304).

\section{Conclusión}

La obra de Nellie Campobello no sólo inicia el rescate del personaje histórico de Villa sino que también lo eleva al rango de héroe y de mito revolucionario. Hemos estudiado, desde una perspectiva estructural y estilística, los medios textualmente detectables que Campobello utiliza para dibujar su subjetiva figura de Villa. Esta conjunción de rasgos literarios con rasgos históricos es justamente, en nuestra opinión, lo que permite construir un mito, puesto que éste "sólo puede tener fundamento histórico" (Berumen, 2006, 35). ${ }^{18}$ En efecto, en los Apuntes, se evocan el personaje de Villa y sus hechos de armas basándose en la realidad pero alterándola al darle el color de la leyenda. Según el DRAE, la palabra mito puede designar a una "persona rodeada de extraordinaria estima", lo que es el caso del Villa que retrata Campobello.

En suma, el Villa de Campobello aparece como perfecto exponente de la heroicidad clásica tal y como es definida por Juan Villegas (1978). Según éste, el héroe clásico actúa como salvador y libertador desde un plano externo, social e histórico. Además, el trayecto de Villa sobre el que indaga Campobello en sus Apuntes ejemplifica lo que Villegas llama la "estructura mítica del héroe". Ésta se refiere a un esquema recurrente en la trayectoria del héroe literario que suele desarrollarse en tres etapas (71). Primero, el héroe tiene que dejar atrás su mundo habitual. Esta salida implica peligros que el protagonista debe superar. Podríamos

${ }^{17}$ Véase el siguiente ejemplo de la sensibilidad del general: "al llegar, sus amigos lo vieron triste y pensativo. Según expresó, eran ya muchos los muchachos que se le habían muerto" (291).

${ }^{18}$ Según Parra $(2005,75)$, Campobello ya había recurrido a la mitificación para rescatar al héroe revolucionario en Cartucho: "the function of myth in Cartucho is to erase, figuratively speaking, the fatal line dividing the dead from the world of the living and the present. The symbols, poeticized images, ironic inversions, plots from folk tales, and other literary devices in these stories all serve the same ideological and sentimental objective: to rescue the historical figure from the tragic circunstances of his death in an effort to ensure that his heroic status remains intact." 
leer de este modo la separación de Villa con su estatuto de campesino desconocido. En este marco, las dificultades que tuvo que enfrentar este personaje estriban en su extracción sociocultural, la cual no lo había preparado al mando militar. La iniciación del héroe, su penetración en "una fuente de poder" (71), marca la segunda etapa de su trayectoria y constituye la aventura stricto sensu. Esta etapa toma muchas veces la forma del viaje y los peligros que entonces se multiplican simbolizan un camino de pruebas en el que se revela el valor del héroe. Finalmente, el protagonista suele regresar a la vida de la que se había alejado al principio y así ocurre cuando, al final de los Apuntes, Villa expresa su deseo de "retirarse a la vida privada a trabajar en el campo" (314) tras haber celebrado el convenio, es decir, tras haber cumplido su misión. A la verdad, estas correspondencias bien podrían reducirse a unas coincidencias, puesto que son los acontecimientos históricos que condicionaron estos desplazamientos de Villa. En cambio, dada la selección de una etapa particular de la vida del Centauro y dado el lirismo con el que se tiñe su figura en este texto, es probable que Campobello dibujara conscientemente su relato como la aventura de un héroe que ella considera como mítico.

Así, aunque plasma el deseo de acabar con las mitificaciones históricas, Campobello crea una nueva mitificación en sus Apuntes. De hecho, el análisis del personaje de Pancho Villa revela la coherencia arquitectural de este texto que se acerca a un objeto propiamente histórico y lo manipula al construirse en base a una red de leitmotivs y de reminiscencias literarias. El Villa pintado por Campobello resulta ser un personaje lleno de contradicciones. Sin embargo, hemos querido demostrar que la construcción de este texto resulta armoniosa precisamente gracias a la coherencia poética anudada con el personaje de Villa.

\section{BIBLIOGRAFÍA}

BAUTISTA AgUILAR, Juan.

2007 "Prólogo", en Nellie Campobello, Obra reunida. México D.F.: FCE, pp. 11-26.

BERUMEN, Miguel Ángel.

2006 Pancho Villa: la construcción del mito. Ciudad Juárez: Océano.

CAILlOIS, Roger.

1938 Le mythe et l'homme. Paris: Gallimard.

CAMPOBELlo, Nellie.

2007 Obra reunida. México D.F.: FCE.

CÁZARES, Laura (ed.).

2006 Nellie Campobello. La revolución en clave de mujer. Ciudad de

México-Toluca: Universidad Iberoamericana-Tecnológico de

Monterrey. 
CORTÉs ORTIZ, Cecilia A.

2010 "Cartucho: los recuerdos infantiles de Nellie Campobello", Hápax, n³, 2010, pp. 3-14.

Covo, Jacqueline (ed.).

1991 La construction du personnage historique. Aires hispanique et hispano-américaine. Lille: Presses Universitaires de Lille.

1997 Historia, espacio e imaginario. Lille: Presses universitaires du Septentrion.

DÍAZ PÉREZ, Olivia C., Florián GrÄFE y Friedhelm SCHMIDT-Welle (eds.).

2010 La Revolución mexicana en la literatura y el cine. MadridFrankfurt: Iberoamericana-Vervuert.

GLANTZ, Margo.

2003 "Vigencia de Nellie Campobello", Anales de literatura española, $\mathrm{n}^{\circ}$ 6, 2003, pp. 185-201.

GUTIÉRREZ DE VELASCO, Luzelena.

2006 "Pancho Villa imaginado por Nellie Campobello", en Laura Cazares (ed.), Nellie Campobello. La revolución en clave de mujer. Ciudad de México-Toluca: Universidad IberoamericanaTecnológico de Monterrey.

HALKIN, Léon-Ernest.

1991 Critique historique. Lieja: Derouaux Ordina.

KAEMPFER, Jean.

1998 Poétique du récit de guerre. Paris: José Corti.

LANNOY, Jean-Louis.

1991 "Pancho Villa, personnage historique et mythe révolutionnaire", en Jacqueline Covo (ed.), La construction du personnage historique. Aires hispanique et hispano-américaine. Lille: Presses Universitaires de Lille, pp. 281-287.

\section{LUCKÁCS, Georg.} 1963 La théorie du roman. Paris: Gonthier.

MARTÍN, René y Jacques GAILLARD.

1990 Les genres littéraires à Rome. Paris: Nathan.

PARRA, Max.

2005 Writing Pancho Villa's revolution: rebels in literary imagination of Mexico. Austin: University of Texas Press.

Peyregne, Françoise.

1991 "La construction du personnage historique (essai de synthèse)", en Jacqueline Covo (ed.), La construction du personnage historique. Aires hispanique et hispano-américaine. Lille: Presses Universitaires de Lille.

PRATT, Marie-Louise.

2004 "Mi cigarro, mi Singer y la revolución mexicana: la voz corporal de 
Nellie Campobello", Revista iberoamericana, n²06, 2004, pp. 253-274.

RUANO GUTIÉRREZ, Marina.

2010 "Temáticas narrativas sobre la Revolución Mexicana (Martín Luis Guzmán y Nellie Campobello)", Sincronía, 2010, http://sincronia.cucsh.udg.mx/ruanowinter2010.htm (30/01/2012).

VANDEN BERGHE, Kristine.

2010 "Alegría en la revolución y tristeza en tiempos de paz. El juego en Cartucho y Las manos de mamá de Nellie Campobello", en Literatura mexicana: Centenario de la Revolución mexicana. Estudios y notas. México: UNAM, pp. 151-170.

VILLEGAS, Juan.

1978 La estructura mítica del héroe en la novela del siglo XX. Barcelona: Planeta.

WHITE, Hayden.

1992 The Content of the Form: Narrative Discourse and Historical Representation. Baltimore: Johns Hopkins University Press.

1999 Storie e narrazione. Ravenna: Longo.

2006 Forme di storia: dalla realtà alla narrazione. Roma: Carocci. 